Rev. Hist., N²8, vol. 1, Enero-Junio 2021: 13-35

ISSN 0717-8832

https://doi.org/10.29393/RH28-2OFCF10002

\title{
Organizando un fracaso. El estanco del salitre. Perú, 1873-1874*
}

Organizing a failure. The saltpeter monopoly. Peru, 1873-1874

Carlos Roberto Flores Soria**

\section{RESUMEN}

El objetivo del trabajo es conocer las acciones del gobierno de Manuel Pardo entre 1873 y 1874 en la implementación del estanco del salitre. Esta medida de carácter fiscal gravaba un impuesto y permitía la participación del Estado en la comercialización del salitre que se exportaba desde Iquique. Se explica, según los actores, el fracaso de la aplicación del estanco. Las fuentes lo constituyen las memorias del presidente, del ministro de Hacienda y Comercio y funcionarios del gobierno.

Palabras claves: Estanco, salitre, gobierno, salitreros.

\section{ABSTRACT}

The objective of the work is to know the actions of Manuel Pardo's government between 1873 and 1874 in the implementation of the saltpeter watertle. A tax measure that recorded a state tax and share in the marketing of the saltpeter exported from Iquique. It explains, from the actors, the failure of the application of the box. The sources are the memoirs of the President of the Republic, the Minister of Finance, and Trade and government officials.

Keywords: Watercrew, saltpeter, government, saltpeters.

Recibido: febrero 2021

Aceptado: mayo 2021

\footnotetext{
* Este artículo es un avance de la tesis de doctor en Historia (Universidad de Tarapacá) patrocinada por el Proyecto Fondecyt № 1170066 .

** Becario del programa del doctorado en Historia de la Universidad de Tarapacá. Magíster en Historia y docente en la Escuela Profesional de Historia de la Facultad de Humanidades, Universidad Nacional Federico Villarreal, Perú. ORCID: https://orcid.org/0000-0002-7624-0540. Correo electrónico: cflores@unfv.edu.pe.
} 


\section{Introducción}

El trabajo tiene por propósito conocer los esfuerzos del gobierno de Manuel Pardo por implementar el estanco del salitre en Iquique, entre 1873 y 1874. Asumimos que el gobierno buscó implementar el estanco como una medida fiscal, pero desconocía la realidad de la industria salitrera. El proceso, complicado, requirió de prolongadas discusiones, avances y postergaciones desde enero de 1873, año en que se aprobó el estanco del salitre. Dos escenarios fueron claves en el propósito: el Congreso de la República en Lima; e lquique (Tarapacá), en el que se concentraba el movimiento industrial y comercial salitrero.

El trabajo se propone dar a conocer cómo se sucedieron los hechos que explican el fracaso de la aplicación del estanco, a partir del discurso de los principales actores, que desde la función que desempeñaron, participaron directamente en el diseño y la viabilidad de aquella medida. Las expectativas del gobierno se complicaron por la falta de oportuna información que se tenía de la región.

Historiográficamente, parte de las investigaciones en torno al estanco del salitre destacan la tesis del carácter fiscal para enfrentar la crisis que vivía la economía del Estado peruano como consecuencia del agotamiento y de la competencia del guano ${ }^{1}$. Por otro lado, otros trabajos también señalan aquella medida como rentista, contextualizando cómo se fue conformando el entorno salitrero y por qué, desde Iquique, los industriales se opusieron a la medida².

\footnotetext{
1 Véase, por ejemplo, en Basadre, Jorge. 1983. Historia de la República del Perú, Lima, Editorial Universitaria. T. V.; Bonilla, Heraclio. 1986. "La crisis de 1872", en Bonilla, H. (editor). Las crisis económicas en la historia del Perú, Lima, Fundación Friedrich Ebert, pp. 167-184; Contreras, Carlos. 1996. "Modernizarse o descentralizar: la difícil disyuntiva de las finanzas peruanas durante la era del guano", en Boletín del Instituto Francés de Estudios Andinos, Vol. 25, N 1, Lima, pp. 125-150; Contreras, Carlos. 2012. La economía pública en el Perú después del guano y del salitre. Crisis fiscal y élites económicas durante su primer siglo independiente, Lima, Instituto de Estudios Peruanos; Flores, Carlos. 2000. "El civilismo y la cuestión del salitre", en Historia. Revista de Historia y Sociedad, N 1, Lima, pp. 39-47; Hunt, Shane. 1984. "Guano y crecimiento en el Perú del siglo XIX", en HISLA. Revista Latinoamericana de Historia Económica y Social, N IV, pp. 35-92; Romero, Emilio. 2005. Historia económica del Perú, Lima, Fondo Editorial de la Universidad Nacional Mayor de San Marcos; Tantaleán, Javier. 1983. Política económico-financiera y formación del Estado: siglo XIX, Lima, Cedep; Tantaleán, Javier. 2012. La gobernabilidad y el leviatán guanero. Desarrollo, crisis y guerra con Chile, Lima, Banco Central de Reserva del Perú-Instituto de Estudios Peruanos; Salas, Miriam. 2011. "La República 1879 a 1883", Historia Marítima del Perú, Lima, Instituto de Estudios Histórico-Marítimos del Perú, tomo $\mathrm{XI}$, vol. 4.

${ }^{2}$ Crozier, Ronald. 1997. "El salitre hasta la guerra del Pacífico: una revisión", en Historia, N 30. Santiago de Chile, 30, pp. 53-126; Donoso, Carlos. 2003. "El puerto de Iquique en tiempos de la administración peruana", en Historia, 36, Santiago, pp. 123-158; Donoso, Carlos. 2007. Estado y sociedad en lquique bajo administración peruana 18211873. Tesis para optar el grado de doctor en Historia, Santiago, Universidad de Chile; Donoso, Carlos. 2018. "Los albores de la industria salitrera en Tarapacá", en Chungara. Revista de Antropología Chilena, Vol. 50, № 3, Arica, pp. 459-470; González, Sergio. 2011. "Auge y crisis del nitrato chileno: La importancia de los viajeros, empresarios y científicos, 1830-1919", en Tiempo Histórico, Nㅜ2, Santiago, pp. 159-178; González, Sergio. 2012. "La resistencia de los tarapaqueños al monopolio salitrero peruano durante el gobierno de Manuel Pardo, desde el estanco a la expropiación (1872-1876)", en Chungara. Revista de Antropología Chilena, Vol 44, № 1, Arica, pp. 101-114; González, Sergio. 2013. "Las políticas salitreras peruana y chilena. ¿Del monopolio estatal a la libertad económica? (18731884)", en Cuadernos de Historia, N³8, Santiago, pp. 39-77; González, Sergio. 2014. "Las inflexiones de inicio y
} 
Ahora bien, planteamos que el estanco del salitre como medida fiscal respondía al carácter patrimonialista del Estado peruano y de la clase política del siglo XIX. Pues -como sostiene Pierre Vilar ${ }^{3}$ - asuntos vinculados al tema de la fiscalidad permiten analizar la situación como una medida económica destinada a resolver un problema en las finanzas del Estado, y evidenciar los conflictos de intereses que se generan coyunturalmente: “Conflictos que, siempre latentes, pero ocasionalmente más agudos, enfrentan por ejemplo a prestamistas y prestatarios, a agricultores e industriales, a importadores y exportadores, a pequeñas y grandes empresas, a veces también de regiones dispares en la nación" ${ }^{4}$. En este caso, Estado (banqueros) y salitreros, Estado y región. En tal sentido, el trabajo apunta a complementar investigaciones relacionadas al gobierno civilista y las medidas que se adoptaron acerca del salitre (estanco y expropiación).

El artículo se sustenta en las memorias de los funcionarios estatales (Presidente de la República, ministro de Hacienda, director de rentas). Estos funcionarios organizaron toda la información relacionada con el estanco al salitre con el propósito de sistematizar cronológicamente las acciones del gobierno: discusión de la ampliación de vigencia de la ley, comunicaciones con el prefecto, la conformación de la comisión administradora. Asimismo, se apoyó en el Diario de debates del Congreso de la República del Perú.

\section{Organización del estanco}

Durante el gobierno de José Balta (1868-1872), se produjo un giro en la legislación fiscal sobre el salitre, se fijó un impuesto a la exportación y se prohibió la adjudicación de terrenos salitreros.

En el transcurso de 1873, el gobierno civilista, entre otras acciones, se dedicó a organizar el funcionamiento del estanco. Fue una medida que experimentó marchas y contramarchas, cuya viabilidad dependió del marco legal que debía aprobar el Parlamento. Así, desde el Congreso de la República, el 26 de marzo, la Cámara de Diputados discutió un dictamen de la Comisión de Hacienda, respecto de los dos meses que se había previsto en la ley del 18 de enero, para que esta se aplicase. Se llegó a considerar que la moratoria tenía dos propósitos: primero, "proporcionar a los negociantes de salitre un tiempo conveniente para la liquidación de sus

término del ciclo de expansión del salitre (1872-1919). Una crítica al nacionalismo metodológico", en Diálogo Andino, Vol. 45, Arica, pp. 39-49; González, Sergio. 2018. "Las primeras estacas del reino salitrero de John Thomas North. El origen del mito", en Cuadernos de Historia, (49), Santiago, pp. 7-36; González Sergio y Lizama, Diego. (2019). "EI estanco salitrero en Tarapacá y el liberalismo peruano: las influencias "castillista" y "civilista" (1844-1873)", en Aldea Mundo. Revista sobre Fronteras e Integración Regional, año 24, № 48, pp. 45-56; Castro, Luis. 2017. "Demanda de ciudadanía, construcción de nación y rentismo minero: los planteamientos regionalistas de los habitantes de la provincia de Tarapacá (1827-1874)”, en Temas Americanistas, № 39, pp. 37-66; Castro, Luis. 2019. “'¿Pertenece a Chile?'. Civilización y desierto, rentismo y subordinación: la formación del territorio nacional en el extremo sur del Perú (Tarapacá 1827-1877)", en Estudos Ibero-Americanos, Vol. 45, № 1, Porto Alegre, pp. 144-157.

${ }^{3}$ Vilar, Pierre. 1980. Crecimiento y desarrollo, Barcelona, Ariel, p. 100.

4 Ídem. 
contratos y arreglo de sus negocios, conforme á las condiciones en que quedaba en adelante por el monopolio el comercio de esa especie" ${ }^{5}$, y segundo, "dar a la vez tiempo al gobierno para preparar los elementos necesarios al establecimiento definitivo de esta nueva institución" ${ }^{\prime 6}$. Aquel dictamen también daba cuenta de las dificultades financieras del gobierno para disponer de los fondos necesarios que permitieran atender el estanco, así como realizar otros proyectos, entre ellos la construcción de ferrocarriles e irrigaciones. Por esta razón, el gobierno solicitó al Congreso facultades para legislar acerca de la postergación de la fecha en que el estanco entraría en vigor, medida necesaria, toda vez que la ley contemplaba su aplicación únicamente durante dos años. Entonces, atendiendo a los dos propósitos mencionados, se decidió postergar durante nueve meses su puesta en funcionamiento.

Por otro lado, el debate sirvió de ocasión para que nuevamente se discutiera la idea de que el estanco era dañino y afectaría la libertad de industria; por el contrario, debería dejarse sin efecto y aprobar un impuesto de 25 centavos de sol por cada quintal de salitre que se exportase ${ }^{7}$. Finalmente, se aprobó el dictamen que la mayoría parlamentaria suscribió, con el que se concedía lo solicitado.

En el contexto descrito, el Presidente, a partir de la autorización dada por el Congreso, el 23 de abril, firmó una ley que autorizaba al gobierno fijar con 45 días de anticipación para que entrase en vigencia la ley del 18 de enero (estanco del salitre), no debiendo ser posterior al 1 de septiembre del mismo año; asimismo, contemplaba "abolir el estanco del salitre" de ser necesario, y permitir que la ley del 18 de enero continuara "surtiendo sus efectos hasta después de nueve meses contados desde la fecha en que el Congreso la derogue" ${ }^{\prime \prime}$. Se trató de una ley que creaba dos posibles escenarios para el estanco del salitre: establecerse o suspenderse.

El 16 de julio de 1873, el ministro de Hacienda y Comercio encargó al prefecto de la Provincia Litoral de Tarapacá realizar los "preparativos necesarios [...] y dictar las providencias inmediatas que para ello sean precisas" ; formar una comisión de productores salitreros para que participaran como miembros de la comisión reguladora en la aplicación del estanco; asimismo, establecer un cuadro para calcular cómo se repartirían los 4'500,000 quintales anuales de producción de salitre que el Decreto Supremo del 12 de julio fijaba para el estanco. La respuesta del prefecto no fue alentadora: "tropiezo con los inconvenientes que resultan de

\footnotetext{
${ }^{5}$ Congreso de la República del Perú. 1873. Diario de debates del Congreso. Cámara de Diputados. Lima, imprenta de El Nacional, p. 278.

6 Ídem.

${ }^{7}$ Congreso de la República del Perú. 1873. Diario de debates del Congreso, p. 281.

8 Dancuart, Pedro E. 1907. Anales de la hacienda pública del Perú. Historia y legislación de la República, (en adelante Anales de la hacienda pública del Perú), Lima, imprenta de La Revista. IX, pp. 181-182.

${ }^{9}$ Izque, J. R. de. 1874. Memoria que presenta al señor ministro de Hacienda y Comercio el director de administración general. Documentos. Estanco del salitre, Lima, imprenta de El Nacional, p. 66.
} 
la negativa de parte de los cinco productores en quienes recayó el nombramiento para servir en la comisión reguladora". Asimismo, manifestaba que los productores, en general, se resistían a aceptar el establecimiento de cuotas en la elaboración del salitre desde setiembre, situación que afectaría cualquier estimación oficial.

El prefecto propuso que la repartición fuese provisional hasta que la instancia administrativa atendiese el reclamo que habían formulado los productores de salitre, que apostaban por la equidad; añadió que tal situación no se podría resolver en noventa días, por lo que recomendaba visitar los establecimientos salitreros (paradas y oficinas). En su opinión, al llegar el " $1^{\circ}$ de setiembre [...] hallará las medidas incompletas y el comercio paralizado en sus jiros". Por ello, consideraba necesario "conciliar los plazos y evitar que haya perturbación ó paralización en la exportación de las oficinas, es lo que mas especialmente se debe estudiar en este momento". Asimismo, sugirió que debían tomarse las medidas necesarias para que el sistema bancario estuviese suficientemente organizado y pudiese garantizar que los productores vendiesen al estanco el salitre de manera anticipada, pues ello permitiría asegurar la producción, ya que:

“...es costumbre en estos negocios vender los cargamentos de salitre anticipadamente, es decir, se mandan vender en Valparaíso diez, veinte y treinta mil quintales, según la escala del productor, entregables de la fecha en que se dá el aviso de efectuarse la venta en uno y hasta dos meses, y por regla general, el salitre por elaborarse en este mes, está vendido en el mes anterior, á fin de obtener fondos para continuar el jiro..." ${ }^{\prime 10}$

Valparaíso era el centro comercial y financiero de la industria salitrera ${ }^{11}$; en consecuencia, en la perspectiva del funcionario, romper aquella cadena productiva tendría implicancias lamentables para su producción y comercio, pues paralizaría cualquier negociación e instalaría la incertidumbre y el desorden en la provincia. Para enfrentar la situación que describe, el prefecto, en tono conciliador, propuso al ministro de Hacienda y Comercio que desde Lima organizara la implementación del estanco del salitre, para lo que se debería disponer con ese propósito de acciones transitorias, entre ellas, nombrar a una comisión para que con equidad asignase las cuotas a cada productor; buscar un punto de partida que permitiese acercar al gobierno y al productor, y un punto intermedio para la industria; fijar la cantidad a entregar al estanco en 2'500,000 quintales y establecer un precio cómodo para todos durante los primeros cuatro meses de aplicación del estanco. De esa manera, “...la industria vendría á acostumbrarse al nuevo sistema introducido á la práctica, y se daría lugar a la regulación de los trabajos preparatorios de la comisión para iniciar el estanco en su propia forma desde el $1 .^{\circ}$

\footnotetext{
10 lbid., p. 72.

11 Pinto, Julio. 1987. "Valparaíso: metrópoli financiera del boom del salitre", en Estrada, Baldomero y Pinto, Julio, Valparaíso 1536-1986, Valparaíso, Instituto de Historia, Universidad Católica de Valparaíso, p. 123.
} 
del año entrante, sin prejuicio de empezar en funciones con ventaja desde el $1 .^{\circ}$ de Setiembre próximo..." ${ }^{\prime 2}$.

De haberse procedido según las recomendaciones del prefecto de Tarapacá, la aplicación del estanco se habría llevado a cabo, desde los primeros pasos, armonizando el interés fiscal del Estado con los intereses de los productores y del comercio. Este hecho habría permitido que las actividades, como la recepción del salitre, la entrega del $25 \%$ de acciones que se ofreció al banco y el método para determinar su grado de pureza, se hubiesen convertido en asuntos de un segundo orden.

Desde Lima otra era la visión que se tenía respecto de cómo se aplicarían las medidas que establecía el decreto sobre el estanco. El ministro de Hacienda y Comercio, en respuesta al documento del prefecto de Tarapacá, el 12 de agosto del mismo año, le escribió para refutar las observaciones de la autoridad regional y señalar que las directivas previstas en el decreto del 12 de julio contribuirían a superar las dificultades que se pudieran presentar, y lo instaba a que se cumplieran estrictamente. Claramente el gobierno desde Lima no entendía lo que pasaba en Iquique. El ministro, en la misiva de retorno, le replicaba y explicaba que el gobierno "ha hecho á los productores concesiones muy especiales, entre ellas, la de que una comisión nombrada por ellos mismos y que merecía toda su confianza, hiciese la designación equitativa de la proporción con que cada uno debiese concurrir á llenar la suma de cuatro y medio millones de quintales fijados en el primer año á la producción del salitre"13.

En caso de que los salitreros persistieran en su negativa de proponer a sus representantes, el artículo 7 -decía el ministro- facultaba al prefecto fijar las proporciones a establecer. Esto obedecía a que de acuerdo con la autoridad financiera no había otra forma de repartir y hacer efectivas las cuotas, pues en el curso de su implementación se irían atendiendo los posibles reclamos que los productores entendían injustos. Esta era la razón por la que esta cuestión no podría retrasar la aplicación de la norma. Por ello instaba al prefecto que para el 1 de septiembre estuviesen formados los cuadros con las cuotas de salitre e iniciar las operaciones del estanco. Para esa fecha también estaba previsto que la Sociedad Administradora del Estanco entraría en funciones a través de habilitaciones a los salitreros, con el propósito de que dispusieran de los medios necesarios para continuar con sus operaciones de producción y comercialización, y, de esa manera, evitar que continuasen contratando con los comerciantes de Valparaíso. Así, la banca limeña buscaba incursionar en la industria salitrera promoviendo una práctica que durante años había incentivado la formación del emporio salitrero. Para el ministro, en esas condiciones, los salitreros evitarían paralizar sus actividades en la pampa salitrera, salvo aquellas decisiones que independientemente asumiera el propietario del

\footnotetext{
12 Izque. 1874, Memoria que presenta al señor ministro de Hacienda, p. 73.

13 Ibid., p. 74.
} 
salitrero. Asimismo, era necesario mantener la cuota de compra fijada para los primeros cuatro meses que se aplicaría en el estanco (septiembre-diciembre de 1873), por cuanto "conforme al art. 10, los precios de venta serán de S. 2.65 hasta 30 de noviembre; de S. 2.75 hasta $1 .^{\circ}$ de marzo; y, siempre mayores en los dos trimestres siguientes" ${ }^{14}$; es decir, una especie de compensación para hacer más convincente la viabilidad del estanco y procurar que no se diese la variación de las cantidades previstas a comprar cada mes. La Sociedad Administradora del Estanco se encargaría de recibir y atender cualquier inconveniente en el desarrollo de las actividades previstas en la ley del estanco. Esa era la respuesta del ministro al prefecto de Tarapacá, a menos de 19 días de que comenzara a regir el estanco al salitre.

En Lima se pensaba que pasada la "primera excitación" de los salitreros, estos irían entendiendo los propósitos y las bondades del no muy novedoso sistema de compraventa que impulsaba el gobierno a favor del presupuesto de la República y de la industria.

\section{La banca limeña y el estanco del salitre}

¿Por qué era necesario encargar a una sociedad la administración del estanco? Consideramos que, hasta entonces, el Estado no había podido consolidar sus instituciones económicas y financieras, motivo por el cual necesitaba de "operadores" privados. Las aduanas, precariamente organizadas, se encargaban de recaudar los impuestos por la importación y la exportación de productos, a través de los principales puertos peruanos (Callao, Islay, Arica, Iquique, entre otros).

Por la forma como había sido diseñado el estanco, se requería de una institución que organizara y ejecutara las directivas, y a la vez, dispusiera del capital necesario para asegurar la compra, el comercio y la continuación de la producción. Para ello, antes de que se publicase la ley que estancaba el salitre, el gobierno llevó a cabo importantes reuniones nocturnas, en las que participaron el presidente, el ministro de Hacienda y Comercio, y los representantes de los bancos, convocados para participar en ese proceso. Las reuniones de iniciaron el 13 de enero de 1873.

El 13 de enero de 1873 se incorporó a la Comisión Consultiva de Hacienda a personajes ligados a la industria salitrera, como Enrique Ayulo, Alfredo Böhl, Juan Gildemeister ${ }^{15}$ (propietario de salitreras Huanza, Argentina, San Juan, San Pedro y Paposo) y Ramón Montero (empresario del entorno ferroviario de Tarapacá), para que, junto a los representantes de la

\footnotetext{
$14 \mathrm{lbid}$, p. 75.

15 Billinghurst, Guillermo. 1889. Los capitales salitreros de Tarapacá, Santiago, imprenta de El Progreso, pp. 15-17; Calle, Marcos. 2014. "Gildemeister y compañía: una empresa de origen alemán en Tarapacá, 1854-1940", en González, Sergio y Parodi, Daniel. (comps.). Las historias que nos unen. Episodios positivos en las relaciones peruanochilenas, siglos XIX-XX, RIL editores, pp. 335-360; Bermúdez, Oscar. 1963. Historia del salitre desde sus orígenes hasta la guerra del Pacífico, Santiago, Ediciones de la Universidad de Chile, pp. 266-271; Hernández, Roberto. 1930. El salitre (resumen histórico desde su descubrimiento y explotación), Valparaíso, Imprenta Fisher, pp. 74, 88.
} 
banca limeña, discutieran las bases para implementar el estanco. Desde entonces hasta el 12 de julio, realizaron prolongadas reuniones de intercambio de ideas, en las que, considerando informes y comunicaciones con la Prefectura de Tarapacá, aprobaron las bases que originaron la Compañía Administradora del Estanco del Salitre ${ }^{16}$.

Las bases, redactadas en 17 cláusulas por la comisión de empresarios y representantes de la banca limeña, establecieron las premisas y los requisitos necesarios para la puesta en marcha del estanco; entre ellos, los siguientes: el monto del capital que debía disponer la Compañía Administradora del Estanco del Salitre, fijado en 4'000,000 de soles, cantidad que se debía dividir proporcionalmente en cuatro mil acciones de mil soles cada una; el porcentaje del capital que debían aportar las instituciones comprometidas en esta operación; la composición del directorio, que debía estar integrado por un representante de cada banco involucrado, un representante de los accionistas y un representante del gobierno; la elaboración de un proyecto de los estatutos de la compañía; la compañía iniciaría sus actividades el 1 de agosto; la compañía debería recibir y pagar S. 2.40 centavos a los productores; el Estado asumiría los gastos por almacenaje, ensayes ${ }^{17}$ y recepción del salitre, y la compañía costearía la administración y vigilancia para evitar la salida no declarada; la compañía exportaría para vender por cuenta del Estado el salitre recibido de los productores que no se vendiera en el Perú a fin de no generar gastos, y asumiría los gastos que ello implicaría (fletes, seguros, entre otros) y, luego, entregaría en efectivo el producto de la venta en los plazos previstos; respecto de los productores que no quisieran vender al estanco, la compañía cobraría la diferencia entre los S. 2.40 y los precios establecidos para las ventas del estanco, y rebajaría de esa diferencia diez centavos por quintal; que la compañía informaría mensualmente al gobierno acerca de la marcha del estanco, entregaría saldos si hubiesen y rendiría cuentas semestralmente (30 de junio y 31 de diciembre) cada año; el plazo de dos años de obligaciones entre el Estado y la compañía de vigencia a partir del 1 de setiembre; que las deudas a la compañía generadas por la venta del salitre o la diferencia que debían pagar los productores se asumirían como deudas al Estado; la autorización para que la compañía estableciera un banco en Iquique con el propósito de que realizase todas las operaciones financieras del estanco, como es el caso de la habilitación de capitales a los productores de salitre; por último, si al concluir la venta de salitre la compañía, que representa al gobierno, no

\footnotetext{
16 Izque. 1874, Memoria que presenta al señor ministro de Hacienda, p. 59.

${ }^{17}$ El ensaye era un procedimiento utilizado en la minería que realizaba un químico o "ensayador" para identificar la cantidad y calidad de una masa con el propósito de precisar sus leyes. En el caso del salitre, un decreto del 12 de julio de 1873 estableció que la Administradora del Estanco pagaría por cada quintal 2. 40 soles "si su ley, comprobada por ensaye fuere de $95 \% "$. En ese orden, si la ley fuese menor o mayor a 95\%, el precio a pagar se reduciría o aumentaría respectivamente. El Peruano, 2 de agosto de 1873, p. 101.
} 
cubría las operaciones (costo y gastos), estas serían pagadas a cuenta de los productos de la aduana de lquique.

Los funcionarios que suscribieron las bases referidas fueron M. Moscoso Melgar, en nombre del Banco La Providencia; J. Pablo Escobar, por el Banco del Perú; y J. Clímaco Basombrío, en representación del Banco Nacional del Perú ${ }^{18}$.

La composición y la distribución del capital previsto en las bases se organizaron de la siguiente manera (ver tabla 1):

Tabla 1

Distribución del capital de la Compañía Administradora del Estanco del Salitre

\begin{tabular}{|c|c|c|}
\hline Sociedad & Capital en soles & $\%$ \\
\hline Bancos Perú, Nacional del Perú y La Providencia & $1^{\prime} 000,000$ & 25 \\
\hline Productores de salitre & $1^{\prime} 000,000$ & 25 \\
\hline $\begin{array}{l}\text { Bancos de los departamentos (Piura, La Libertad, Arequipa y } \\
\text { Tacna) }{ }^{19}\end{array}$ & 800,000 & 20 \\
\hline Público & $1^{\prime} 200,000$ & 30 \\
\hline Total & $4^{\prime} 000,000$ & 100 \\
\hline
\end{tabular}

Fuente: Elaboración propia a partir de J. R. de Izque. 1874. Memoria que presenta al señor ministro de Hacienda, p. 59.

El primer directorio de la Compañía Administradora del Estanco del Salitre quedó conformado por funcionarios como Juan T. Calderoni, representante del Banco del Perú; Federico Ford, representante del Banco Nacional del Perú; José Albarracín, representante del Banco La Providencia, y José Manuel Tirado, director de rentas del Ministerio de Hacienda y Comercio, como representante provisional del gobierno ${ }^{20}$. ¿Qué beneficios recibiría la Administradora del Estanco por su participación en esta empresa? Las bases consideraban pertinentes una serie de reembolsos compensatorios. La tabla 2 muestra la relación entre las operaciones y los porcentajes de comisión correspondientes.

Por las características de las operaciones y comisiones a favor de la Administradora, y por la $7^{a}$ cláusula se establecía que el Estado asumiría: "todos los gastos que causasen el recibo, el almacenaje si hubiese lugar á él, los ensayes y las entregas del salitre y en general todos los que corresponden"21. Es pertinente afirmar la similitud de este mecanismo con el sistema de consignaciones, una de las formas de venta que se adoptó en los negocios del guano. En síntesis, siguiendo a J. M. Rodríguez, se tiene que el Estado asumía los gastos mayoritarios, a

\footnotetext{
18 Izque. 1874, Memoria que presenta al señor ministro de Hacienda, p. 61.

${ }^{19}$ Rodríguez, J. M. 1895. Estudios económicos y financieros y ojeada sobre la hacienda pública del Perú y la necesidad de su reforma, Lima, Librería, Imprenta y Encuadernación Gil, p. 324.

20 Izque. 1874, Memoria que presenta al señor ministro de Hacienda, p. 66; Camprubi, Carlos. 1957. Historia de los bancos en el Perú (1860-1879), Lima, Editorial Lumen, p. 109; Morón, Eduardo. 1993. La experiencia de banca libre en el Perú: 1860-1879, Lima, Editorial Universidad del Pacífico, p. 22.

21 Izque. 1874, Memoria que presenta al señor ministro de Hacienda, pp. 59-60.
} 
la vez que entregaba la nueva riqueza (el salitre) en forma de monopolio a la Compañía Administradora del Estanco 22 .

Tabla 2

Comisiones que recibiría la Compañía Administradora del Estanco del Salitre

\begin{tabular}{|c|c|c|}
\hline Operación & Comisión & Condición \\
\hline $\begin{array}{c}\text { Desembolsos a cuenta del Estado en } \\
\text { lquique }\end{array}$ & $9 \%$ & En caso de hacerse en Europa \\
\hline $\begin{array}{c}\text { Abono de flete y gastos } \\
\text { Si se da descuento del Banco de } \\
\text { Inglaterra }\end{array}$ & $5 \%$ & Si excede el 4\% \\
\hline $\begin{array}{c}\text { Sobre el producto bruto del salitre } \\
\text { Salitre exportado fuera del estanco }\end{array}$ & $2.5 \%$ & $\begin{array}{c}\text { Venda o exporte el salitre en el } \\
\text { extranjero. }\end{array}$ \\
\hline Fletes & $\begin{array}{c}\text { 3 centavos de sol por } \\
\text { quintal }\end{array}$ & Si supera 5'000,000 no se cobra. \\
\hline
\end{tabular}

Fuente: Elaboración propia a partir de J. R. de Izque. 1874. Memoria que presenta al señor ministro de Hacienda, p. 60.

El 5 de agosto, el ministro de Hacienda dispuso que el funcionario Fabricio Cáceres viajara a Iquique para que se encargase de las actividades preparatorias, que luego permitirían implementar el estanco. Allí debía permanecer dos meses; asimismo, por la tarea a realizar, recibiría una remuneración de mil soles y los gastos que demandaran su viaje. Producto de su estadía, elaboró un informe sobre la situación de lquique y las actividades sobre la producción del salitre, de la cual puso en conocimiento del ministro a fines de setiembre ${ }^{23}$. Acerca de la industria del salitre, anotó que existían 122 oficinas establecidas y 23 en vías de plantificación, cuya producción anual no llegaba a seis millones de quintales. También que estos eran exportados por diferentes puertos, según la ubicación de la oficina que los producía: por Pisagua (25), Junín (la Compañía de Tarapacá), Mejillones (37), lquique (59), Molle (1) y Patillos (9). Señaló que en agosto el precio del quintal de salitre fluctuaba entre S. 1.97 y 2.10 centavos; al finalizar su informe concluyó que lquique necesitaba de la atención del Estado ${ }^{24}$.

Del 1 de setiembre, fecha en que el estanco empezaría a operar, hasta el 31 de diciembre de 1873, el gobierno había proyectado captar 375,000 quintales de salitre cada mes. En relación con la fecha de inicio, El Comercio, importante periódico de Iquique, informó que, debido a la intervención de las autoridades locales, las operaciones de la Compañía del Estanco se iniciaron el 1 de noviembre del mismo año, es decir, dos meses después del día previsto. Acerca de los dividendos y de la cantidad de quintales comercializados, el periódico reveló que,

\footnotetext{
22 Bonilla, Heraclio. 1984. Guano y burguesía en el Perú, Lima, Instituto de Estudios Peruanos, pp. 17-38; Rodríguez. 1895, Estudios económicos y financieros, p. 327.

23 Izque. 1874, Memoria que presenta al señor ministro de Hacienda, pp. 66-67 y 79-86.

24 Ibid., p. 84.
} 
desde setiembre de 1873 hasta junio de 1874, es decir, en el curso de diez meses, la Compañía Administradora del Estanco había logrado recaudar S. 609,027.90, monto que equivalía a exportar 4'050,195.59 quintales ${ }^{25}$. A continuación, el desagregado mensual del dinero recaudado y de los quintales de salitre exportado:

Tabla 3

Derechos recaudados por la Compañía del Estanco del Salitre 1873-1874

\begin{tabular}{|c|c|c|c|c|c|}
\hline \multirow[b]{2}{*}{ Año } & \multirow[b]{2}{*}{ Mes } & \multicolumn{3}{|c|}{ Puertos } & \multirow{2}{*}{$\begin{array}{c}\text { Totales en } \\
\text { soles }\end{array}$} \\
\hline & & Pisagua & Mejillones & Iquique & \\
\hline \multirow{4}{*}{1873} & Septiembre & $11,613.05$ & -- & -- & $11,613.05$ \\
\hline & Octubre & $12,947.32$ & -- & -- & $12,947.32$ \\
\hline & Noviembre & $16,747.05$ & $18,763.17$ & $70,062.94$ & $105,573.16$ \\
\hline & Diciembre & $15,222.20$ & $7,975.80$ & $41,156.94$ & $64,354.94$ \\
\hline \multirow{6}{*}{1874} & Enero & $21,034.11$ & $13,946.47$ & $47,023.48$ & $82,004.06$ \\
\hline & Febrero & $17,166.07$ & $3,230.41$ & $42,870.47$ & $63,266.95$ \\
\hline & Marzo & $29,214.64$ & $12,150.32$ & $58,339.05$ & $99,704.01$ \\
\hline & Abril & $8,670.76$ & $16,007.61$ & $48,296.39$ & $72,974.76$ \\
\hline & Mayo & $5,068.76$ & $5,153.75$ & $36,992.97$ & $47,215.48$ \\
\hline & Junio & $8,033.97$ & -- & $41,340.49$ & $49,374.46$ \\
\hline \multicolumn{2}{|c|}{ Totales en soles } & $145,717.64$ & $77,227.53$ & $386,082.73$ & $609,027.90$ \\
\hline
\end{tabular}

Fuente: El Comercio. Iquique 5 de julio de 1874. Año 1, № 2, p. 3.

La tabla 3 consigna datos que recogió El Comercio de lquique acerca de la exportación directa que realizaron los salitreros, quienes pagaron a la Administradora una tasa de escala móvil que iba de 15 a 25 centavos por quintal. Las cantidades se coligen de las exportadas en los puertos que refieren.

De acuerdo a las estadísticas oficiales, los ingresos económicos que la Dirección de Administración General del Ministerio de Hacienda y Comercio recaudó por la exportación de 4'025,061 quintales de salitre que realizaron los productores que optaron por la exportación directa sin estanco fueron (ver tabla 4):

${ }^{25}$ El Comercio (Iquique), 5 de julio de 1874. 
Tabla 4

Exportación de salitre por la Compañía Administradora del Estanco 1873-1874

\begin{tabular}{|c|c|c|c|c|c|}
\hline \multirow[b]{2}{*}{ Año } & \multirow[b]{2}{*}{ Mes } & \multicolumn{3}{|c|}{ Puertos } & \multirow{2}{*}{$\begin{array}{l}\text { Totales en } \\
\text { quintales }\end{array}$} \\
\hline & & Pisagua & Mejillones & Iquique & \\
\hline \multirow{4}{*}{1873} & Septiembre & $77,420.44$ & -- & -- & $77,420.44$ \\
\hline & Octubre & $86,324.28$ & -- & -- & $86,324.28$ \\
\hline & Noviembre & $111,647.06$ & $125,087.87$ & $467,086.11$ & $703,821.04$ \\
\hline & Diciembre & $101,481.35$ & $53,171.99$ & $274,379.36$ & $429,032.70$ \\
\hline \multirow{6}{*}{1874} & Enero & $140,227.43$ & $92,976.50$ & $313,489.67$ & $546,693.60$ \\
\hline & Febrero & $114,440.43$ & $21,536.08$ & $285,802.93$ & $421,779.44$ \\
\hline & Marzo & $194,764.27$ & $81,002.20$ & $388,927.12$ & $664,693.59$ \\
\hline & Abril & $57,805.08$ & $106,717.42$ & $321,976.22$ & $486,498.72$ \\
\hline & Mayo & $33,789.81$ & $34,358.41$ & $246,620.15$ & $314,768.37$ \\
\hline & Junio & $53,559.82$ & -- & $275,603.59$ & $329,163.41$ \\
\hline \multicolumn{2}{|c|}{ Totales en quintales } & $971,459.97$ & $514,850.47$ & $2^{\prime} 573,885.15$ & $4^{\prime} 060,195.59$ \\
\hline
\end{tabular}

Fuente: El Comercio. Iquique, 5 de julio de 1874. Año 1, n. ${ }^{\circ} 2$, p. 3.

De los datos que muestra la tabla 5, conviene destacar que, desde el 1 de setiembre de 1873 al 30 de abril de 1874, el Estado peruano percibió 483,007.41 soles independientemente del monto que obtuvo la Compañía Administradora del Estanco. El ingreso monetario no era despreciable, si se considera que, por mucho tiempo, la exportación del salitre no había registrado ningún aporte significativo a las finanzas del Estado. En palabras del director de administración, antes de que funcionara el estanco, la industria del salitre: "gozaba del privilegio de no contribuir directamente á los gastos de la Nacion, concurre hoy á estos con una cuota proporcionada á sus rendimientos, en virtud de las leyes dictadas con el objeto de estancar la venta de este artículo" ${ }^{26}$.

Tabla 5

Importe obtenido por exportación directa del salitre por 0.15 centavos. Septiembre 1873 - abril 1874

\begin{tabular}{|l|c|}
\hline \multicolumn{1}{|c|}{ Período } & Total en soles \\
\hline 1 de septiembre a 31 diciembre de 1873 & $231,608.22$ \\
\hline 1 de enero a 30 de abril de 1874 & $251,399.19$ \\
\hline La Compañía Administradora del Estanco & $120,751.83$ \\
\hline Total & $603,759.24$ \\
\hline
\end{tabular}

Fuente: Anales de la hacienda pública. 1907, tomo IX, p. 33

${ }^{26}$ Izque. 1874, Memoria que presenta al señor ministro de Hacienda, p. XXVI. 
En ese contexto, el gobierno gestionó anticipos de dinero a cuenta de los ingresos de la venta del salitre. Así, entre diciembre de 1873 y setiembre de 1874, solicitó a la Compañía Administradora del Estanco, en 12 requerimientos, la entrega de S. 221,916.75 para la caja fiscal del departamento de Lima, sin especificar su destino ${ }^{27}$. Como era lógico, la Administradora cobraba al gobierno los desembolsos e intereses respectivos. Por ejemplo, en marzo de 1874, el ministro de Hacienda Camilo N. Carrillo dispuso que la mencionada Administradora del Estanco realizara la entrega:

“...a orden del Banco Nacional del Perú la tercera parte de los productos del derecho de exportación sobre el salitre que se recaude por el mes de abril próximo, hasta completar la cantidad de 70000 soles importe de la tercera parte del préstamo que con esta fecha han hecho al Supremo gobierno los Bancos del Perú, el Nacional del Perú y el de La providencia...". ${ }^{28}$

Finalmente, según el ministro de Hacienda y Comercio $^{29}$, hasta diciembre de 1874 , por los derechos fiscales (de 0.15 centavos por quintal) del salitre exportado, el Estado registró en sus ingresos las cantidades siguientes:

Tabla 6

Exportación y producción del salitre setiembre 1873-1874

\begin{tabular}{|l|c|c|}
\hline \multicolumn{1}{|c|}{ Periodo } & Quintales & Total en soles \\
\hline 1 de septiembre al 31 diciembre de 1873 & $1^{\prime} 930,068.52$ & $289,510.26$ \\
\hline Todo el año de 1874 & $5^{\prime} 595,314.89$ & $839,297.22$ \\
\hline Total & $7^{\prime} 525,383.41$ & $1^{\prime} 128,807.48$ \\
\hline
\end{tabular}

Fuente: Elaboración propia a partir de Anales de la hacienda pública, 1908, tomo X, p. 91.

Los datos consignados en las tablas 5 y 6 demuestran que las recaudaciones se incrementaron significativamente en un año y cuatro meses, no obstante que el precio del quintal de salitre había disminuido de 14 en 1873 a 12 chelines en 1874 . Asimismo, evidencian que los salitreros evitaron el estanco y decidieron exportar libremente. Siendo así la situación, el estanco estaba en camino a quedar en saco roto.

Abundando en cifras, J. M. Rodríguez, a partir de las estimaciones elaboradas por la Dirección de Rentas del Ministerio de Hacienda y Comercio para 1875, señaló que la Compañía Administradora del Estanco había logrado recaudar, hasta junio de ese año, la cantidad de S./4'760,283.27 por la exportación de 18'697,788.32 quintales de salitre. Esto sin considerar

\footnotetext{
${ }^{27}$ Salas, Miriam. 2011. Historia Marítima del Perú, Lima, Instituto de Estudios Histórico-Marítimos del Perú, tomo XI, vol. 4, p. 554.

28 Citado por Salas, 2011, Historia Marítima del Perú, p. 554-555.

${ }^{29}$ Los ministros de Hacienda y Comercio que estuvieron a cargo de aquella cartera fueron: José María de la Jara de setiembre de 1872 al 7 de noviembre de 1873, reemplazado por el capitán de navío Camilo N. Carrillo, quien renunció el 24 de mayo de 1874 y lo sucedió Juan Ignacio Elguera. Ver: Anales de la hacienda pública, 1907, tomo IX, p. 15.
} 
los 166,216 quintales que por cuenta del Estado había exportado. El monto que la Compañía había percibido por comisión ascendía a S./560,933, a "razón de 3 centavos por quintal" ${ }^{30}$. Para aquel año, el resultado no fue alentador cuando se inició la discusión de la expropiación.

\section{El fracaso del estanco}

En 1874 una publicación extraordinaria del periódico limeño El Nacional hizo un recuento de lo que ocurrió el año anterior con el estanco del salitre. Destacó que, desde fines de 1872 y durante todo 1873, la aplicación de este sistema generó una de las dificultades más serias al gobierno de Manuel Pardo. Esto por causa de los vaivenes en la toma de decisiones y demoras en la implementación de la medida, y por causa de la resistencia de los salitreros y la hostilidad que estos ejercieron contra los comisionados en Iquique. El periódico concluye que el salitre no había sido estancado ni el gobierno había logrado utilidades y que por tales circunstancias los salitreros se encontraban afrontando los daños de aquella medida ${ }^{31}$. Tal era el panorama que se retrataba de cara a 1874 .

En la memoria que el director de rentas, José M. Tirado, dirigió al ministro de Hacienda el 30 de junio de 1874, el funcionario reportó la situación como desfavorable y las razones que la habrían motivado:

“...esa ley [referida al estanco] no ha surtido sus efectos a pesar de las medidas adoptadas por el Gobierno; porque los productores no se han presentado a la formación de los cuadros que determinaran las cuotas que debían producir, ni la Comisión que en efecto de ellos debía hacerlo, pudo reunirse, no obstante, los esfuerzos de la autoridad política de la provincia, que se veía obligada a cumplir las disposiciones dictadas por el Gobierno sobre el particular" ${ }^{32}$

Pero las razones del fracaso del estanco fueron explicadas con mayor detalle en la memoria presentada por el ministro de Hacienda Juan Ignacio Elguera a la legislatura ordinaria del Congreso de la República de 1874. Recordó al pleno del Congreso que, inicialmente, se presentó un proyecto que apuntaba a establecer un impuesto de exportación variable que tuviese como referencia el precio del salitre y las utilidades del salitrero; $y$, de ser posible, libre de impuesto, siempre y cuando el precio no superase la cantidad mínima establecida como costo de producción. Y, sin embargo, como esta medida no había prosperado y el Congreso aprobó la ley del estanco, el ministro manifestó su contrariedad:

\footnotetext{
30 Rodríguez. 1895, Estudios económicos y financieros, p. 326.

${ }^{31}$ El Nacional. 1873. Revista general [edición extraordinaria del 1 de enero de 1874], pp. 43-44.

32 Citado por San Cristóbal, Evaristo. 1945. Manuel Pardo y Lavalle. Vida y obra, Lima, Gil Editores. p. 55. Era una publicación de algunos miembros del Partido Civil, siendo los más visibles Juan Francisco Pazos, Francisco Flores Chinarro y Agustín Chacaltana.
} 
“...esa ley fue objeto de una viva oposición por parte de los productores del salitre, quienes formulaban contra él todo género de argumentos, e influían en el ánimo de los miembros del Congreso para que lo rechazasen, insinuando como medida más ventajosa, tanto para la industria de Tarapacá como para el Gobierno, la de autorizar a éste para comprar el salitre a un precio fijo, constituyéndose así en solo expendedor del artículo". ${ }^{33}$

En efecto, se había propuesto, como alternativa, crear una renta para el Estado y hacer efectivo en el orden comercial el monopolio de un insumo (el nitrato de soda) que la naturaleza había dotado al Perú. Este hecho, según el ministro, era posible porque "(...) la producción del salitre en Tarapacá, no está sujeta a la competencia de ninguna nación del mundo; puede imponer sus precios al mercado europeo $(. . .)^{34}$. Las posibilidades de hacer prevalecer aquel monopolio era una condición para evitar que la pujante industria salitrera con mucho futuro, después del guano, no se viera afectada por los vaivenes del mercado europeo y arruinara a los salitreros.

En nuestra consideración, en su planteamiento, el ministro Elguera no tomó en cuenta dos cuestiones importantes. La primera guarda relación con el hecho de que el mercado condicionaba el consumo y no el monopolio que se pretendía ejercer desde las salitreras de Tarapacá. Acerca de este punto, un escrito publicado en 1872, en pleno debate de la ley del estanco, sentenciaba: "El monto del espendio de una mercancia, puede ser previsto con más ó ménos acierto, pero no fijado de antemano. Esa operación la hace el consumo, es un fenómeno á posteriori y no á priori. Por consiguiente, la cifra oficial, pecará unas veces por exceso y otras por defecto" 35 .

La segunda cuestión tenía que ver con los fuertes intereses de nacionales y extranjeros (bancos y habilitadores) afincados en Tarapacá, vinculados mejor con Valparaíso que con Lima. Al respecto, el citado documento señalaba que los impulsores del estanco no han considerado "que los beneficios obtenidos por los especuladores de Valparaíso, provienen principalmente del comercio de artículos de primera necesidad, del cobro del $8 \%$ de intereses de habilitaciones y del $4 \frac{1}{2} \%$ por derechos de comisión de compra y venta" ${ }^{36}$.

Otro de los factores que, según el ministro, repercutió en el fracaso del estanco fue la opinión pública, la cual no habría contribuido a generar un clima favorable para aplicar la medida, debido a que era menester implementarlo sin emplear la fuerza o violencia, pues, por el contrario, expresó: “Desgraciadamente, [...] ha juzgado las cosas de distinto modo, y la mayoría del país se ha pronunciado abiertamente contra el estanco, apoyando así a los grandes productores del salitre" ${ }^{37}$.

\footnotetext{
33 Elguera, Juan I. 1874. Memoria presentada por el ministro de Hacienda y Comercio a la legislatura ordinaria de 1874, Lima, Imprenta de La Opinión Nacional, p. 17.

34 lbid., p. 18.

35 Anónimo. 1872. Impugnación del proyecto de estanco del salitre de Tarapacá, Lima, Imprenta de La Patria, p. 13.

${ }^{36}$ Elguera. 1874, Memoria presentada por el ministro de Hacienda, pp. 17-18.

37 Ibid., p. 19.
} 
Por otro lado, sostuvo que los pequeños productores de paradas $^{38}$ fueron los más interesados en que el estanco prosperara, ya que el precio que ofertaba les aseguraba continuidad en la producción. Mientras, del lado de los llamados "grandes productores", la oposición y resistencia fue general debido a que las máquinas y tecnologías que habían incorporado a sus oficinas los salitreros les permitían superar la producción de salitre prevista en las directivas que establecía el estanco. También la oposición era manifiesta del lado de los habilitadores, quienes veían peligrar los beneficios que obtenían de los capitales que prestaban a pequeños y medianos industriosos salitreros. En todo este conflicto, el Estado resultó ser el perdedor, porque, finalmente, no logró imponer el tributo de los S./2.40 centavos por quintal de salitre ni pudo controlar la producción. Defendió abiertamente el estanco como una de las medidas más razonables y criticó a los salitreros que culpaban al gobierno de arruinarlos, pues, desde la visión del ministro, se dieron dos situaciones paradójicas: primero, cuando se comenzó a discutir la posibilidad de establecer el estanco, los precios eran favorables para los productores y, segundo, que los salitreros tuvieron que cerrar sus oficinas luego de que se dejara sin efecto el estanco, debido a que bajó el precio del quintal de salitre. En ese contexto, la resistencia de los salitreros se había expresado en la negativa de entregar información sobre la producción de sus respectivas oficinas, así como preferir exportar libremente pagando 15 centavos por quintal.

Para los hombres administradores de las finanzas del Estado, la imposición del estanco fracasó por la disidencia de los productores, y si estos se estaban arruinando era porque no podían producir al precio que en el momento regía en el mercado, lo que afectaba al país y beneficiaba a los agricultores europeos. Es decir, el Estado no pudo comprar ni vender al precio que fijaba la ley del estanco (dos soles cuarenta centavos), pues los salitreros habían decidido vender libremente. El ministro dejó entonces, en manos del Congreso, resolver el problema, que en el debate público se llamó la cuestión salitre.

En ese estado de cosas, en su mensaje a la legislatura ordinaria del 28 de julio de 1874, el presidente Pardo dejó entrever que la aplicación del estanco había permitido obtener, a favor de las finanzas, recursos en pequeñas proporciones y con dificultades, "porque el estanco mismo no ha podido establecerse, a pesar de todas las razones que lo aconsejaron"39.

Pardo había sido un convencido de que la medida iba a ser provechosa para el Estado y para los productores de salitre. Sin embargo, con un Congreso de la República muy activo, consideró necesario generar actitudes de "buena voluntad de muchos" para materializar y viabilizar el

\footnotetext{
38 Las Paradas fueron establecimientos asociados a una técnica de elaboración de salitre. La "facultad productiva" de una "Parada" era cuantitativamente inferior a la de una "Máquina" que en la década de 1870 transformó la industria salitrera en Tarapacá. Según Bermúdez, un pequeño productor estimaba que una oficina de "Paradas" podía producir 20000 quintales de salitre por año. Billinghurst. 1889, Los capitales salitreros de Tarapacá, pp. 1519; Bermúdez. 1963, Historia del salitre desde sus orígenes hasta la guerra del Pacífico, pp. 136-139; 422-423.

39 Pardo, Manuel. 1874. Mensage del Excmo. señor D. Manuel Pardo, presidente Constitucional de la República a la legislatura ordinaria de 1874, Imprenta del Estado, p. 15.
} 
estanco. Por el contrario, el ambiente social y político fue adverso, y se convirtió en un obstáculo, pues "la opinión pública, tanto en la provincia de Tarapacá, como en el país en general, se ha manifestado completamente opuesto a esa medida" ${ }^{40}$.

Desde las perspectivas del ministro de Hacienda y Comercio, y del propio presidente, el estanco había fracasado y los únicos ganadores habían sido los compradores europeos. Si bien Pardo había logrado coyunturalmente establecer alianzas políticas y sociales con los poderes regionales ${ }^{41}$, la región tarapaqueña le era adversa ${ }^{42}$. En consecuencia, el salitre que había sido considerado como la salvación de la crisis fiscal debía tener otra salida. El gobierno civilista debía afrontar directamente esta nueva dificultad, reto que sus partidarios se propusieron solucionar a través de la expropiación. Si bien la oposición había condenado el estanco, la medida siguiente continuaría enfrentando directamente a los salitreros fuertemente organizados.

Así, según la evaluación del ministro respecto de los ingresos previstos para el Presupuesto de la República de 1873 , los que provendrían del salitre fueron estimados en 420,000 soles, para el de 1874 en 2'250,000 soles ${ }^{43}$; es decir, de un año a otro los ingresos se quintuplicarían, pronóstico que no se cumplió.

Ahora bien, algunos personajes contemporáneos a la experiencia peruana del estanco, como Miguel Cruchaga, estudioso de la hacienda pública chilena, afirman que en 1881 el estanco no cumplió con los objetivos trazados por el gobierno de Pardo y esta fue "combatida por todos los productores de salitre, combatida también por los consumidores [...] La ley no alcanzó dominar el sistema común de alzas y bajas de precios" ${ }^{44}$.

Los opositores del estanco sostuvieron que la caída del precio del salitre contribuyó al fracaso de aquella medida y afirmaron que "hoy se quiere poner á la industria salitrera la disyuntiva, ó de morir bajo el yugo de onerosas contribuciones, ó de pasar a manos del Estado" ${ }^{\prime 4}$.

Finalmente, Rodríguez era un convencido de que el estanco limitaba la libertad de industria y que el gobierno debió optar por "el sistema de explotación libre, gravando la exportación con un impuesto moderado" ${ }^{46}$ que hubiese proporcionado una renta fiscal $y$, a su vez, hubiese estimulado el desarrollo de las empresas salitreras en un clima de libertad.

\footnotetext{
40 Ibídem.

41 Mc Evoy, Carmen. 1997. La utopía republicana, Lima, Fondo Editorial PUCP. pp. 138-149; Mücke, Ulrich. 2010. Política y burguesía en el Perú. El Partido Civil antes de la guerra con Chile, Lima, Instituto Francés de Estudios Andinos - Instituto de Estudios Peruanos, pp. 281-300.

42 Donoso, Carlos. 2007. Estado y sociedad en Iquique bajo administración peruana 1821-1873 [Tesis para optar el grado de doctor en Historia, Santiago, Universidad de Chile]. Repositorio ANID.

${ }^{43}$ Elguera. 1874, Memoria presentada por el ministro de Hacienda, p. 12.

${ }^{44}$ Cruchaga, Miguel. 1929. Salitre y guano. Editorial Reus, p. 254.

45 Anónimo. 1874. Huano y salitre. Publicaciones hechas por la prensa en defensa de los legítimos intereses de la industria salitrera, Lima, Imprenta de EI Nacional, p. 10.

${ }^{46}$ Rodríguez. 1895, Estudios económicos y financieros, p. 223.
} 


\section{Reflexiones Finales}

¿Qué implicancias económicas y políticas generó la ley del estanco del salitre para el gobierno civilista y los salitreros de Tarapacá? Como hemos visto, los discursos de los ministros evidenciaban que el conflicto de intereses entre el Estado y los salitreros, especialmente, a través de la conformación de la Compañía Administradora del Estanco, integrada por los miembros de la banca limeña, implicó -como sostiene Castro- "la emergencia de una disputa política no menor entre los intereses (...) rentistas del aparato estatal central y la opción de los tarapaqueños de hacer de sus potencialidades productivas mineras, pero también agrícolas y comerciales, una plataforma de desarrollo socioeconómico más integral” ${ }^{47}$.

La formación de capitales de los banqueros limeños, expresión burguesa del civilismo ${ }^{48}$, durante la llamada era del guano, se debió a la activa intermediación que realizó el mercado externo en representación del Estado del comercio guanero ${ }^{49}$. Esto implicó que, cuando el civilismo llegó al gobierno en setiembre de 1872, ya tenía el soporte financiero para intervenir en el comercio salitrero, lo que propició su participación, a través del estanco (1873) y luego en la expropiación de la industria salitrera (1875). No obstante que Manuel Pardo era un confeso político liberal ${ }^{50}$ sus decisiones gubernamentales fueron contradictorias. Pues -como plantea Contreras- el Estado peruano había "fundado sus finanzas en el sector más promisorio, haciendo de las elites los operadores o contratistas de sus estancos" ${ }^{\prime 51}$. Los estancos, en la estructura de las finanzas republicana, constituían una herencia colonial estrechamente relacionada a la práctica de un monopolio; por ejemplo, el tabaco, el papel sellado, la brea, la pólvora y los naipes. Los ingresos provenientes del guano cambiaron la organización de la fiscalidad estatal, pues privilegió su aporte en forma de renta patrimonial, es decir, "una renta derivada de la propiedad sobre un recurso o bien"52. En él, el Estado asumía la propiedad de los recursos exportables y "podía optar por ceder a particulares la explotación temporal de tales recursos a cambio de la percepción de una renta, canon o regalía, constituyéndose esta entrada una fuente importante de sus finanzas" ${ }^{\prime 53}$.

Por ello los tarapaqueños entendieron que el estanco no solo era una medida fiscal coyuntural en forma de impuesto, sino que también buscaban monopolizar la producción y el comercio

\footnotetext{
47 Castro, Luis. 2017. "Demanda de ciudadanía, construcción de nación y rentismo minero: los planteamientos regionalistas de los habitantes de la provincia de Tarapacá (1827-1874)", en Temas Americanistas, Sevilla, №39, p. 65.

48 Mücke, 2010. Política y burguesía en el Perú. pp. 37-63.

49 Bonilla. 1984, Guano y burguesía en el Perú, pp. 17-59.

${ }^{50}$ Mc Evoy. 1997, La utopía republicana, pp. 128-132.

${ }^{51}$ Contreras. 2012, La economía, p. 33.

52 Contreras, Carlos. 2004. El aprendizaje del capitalismo. Estudios de historia económica y social del Perú republicano, Lima, Instituto de Estudios Peruanos, p. 71.

${ }^{53}$ Contreras. 2012, La economía, p. 32.
} 
salitrero. En ese contexto, la oposición al estanco se produjo desde dos frentes: Lima e lquique. En Lima la oposición dio paso a diversas publicaciones y discusiones en la prensa ${ }^{54}$. En Iquique la manifestación del descontento se expresó en comentarios editorializados en dos importantes medios de comunicación local: El Comercio y El Mercurio. Los mensajes de alarma y ruina se apoderaron del debate público.

Por ejemplo, desde Iquique, el 14 de enero de 1873, El Mercurio anunciaba que "la ruina de la Provincia de Tarapacá está decretada fatalmente" ${ }^{55}$. Así, en días sucesivos, llamaban la atención acerca de los riesgos que para la región podrían generar los efectos del estanco, sobre todo el monopolio que se quería imponer desde Lima. Igualmente, El Comercio daba cuenta de la resistencia de cierto sector de salitreros a entregar a la Administradora del Estanco reportes de la producción de salitres de sus oficinas ${ }^{56}$.

En la opinión de los críticos y opositores, "el estanco amenazaba la independencia de los salitreros"57. La idea dominante era que la medida afectaba la "iniciativa privada" y "las empresas más grandes en particular, como la Tarapacá Nitrate Company, resentían la asignación de cuotas" ${ }^{58}$. Como acciones de protesta, los salitreros se agruparon y "cabildearon al presidente, al Congreso y a la prensa, amenazaron también con resistir las investigaciones oficiales" ${ }^{\prime 59}$.

Luis Esteves, que publicó en plena ocupación chilena de Lima uno de los primeros libros sobre la historia económica peruana, consideró que el estanco puso de manifiesto dos hechos: primero, la actitud avara e inconsecuente de los industriales salitreros, a quienes no les interesó conocer que el orden y la prudencia que el Estado, a través del monopolio y de la limitación de la producción, elevarían los precios y, segundo, los intereses de Chile por el salitre ${ }^{60}$.

\footnotetext{
${ }^{54}$ Anónimo. 1874. Huano y salitre, Publicaciones hechas por la prensa, pp. 30-34 y 119-131.

55 El Mercurio (Iquique), 14 de enero de 1873.

${ }^{56}$ El Comercio (Iquique). 5 de julio de 1874.

${ }^{57}$ Miller, Rory y Greenhill, Robert. 2011. “El gobierno y el comercio del salitre, 1873-1879”, en Miller, Rory, Empresas británicas, economía y política en el Perú 1850-1934, Lima, Banco Central de Reserva del Perú - Instituto de Estudios Peruanos, p. 42.

58 Miller y Greenhill. 2011, "El gobierno y el comercio del salitre", p. 43. La Compañía de Salitres de Tarapacá (Tarapacá Nitrate Company) se formó en noviembre de 1865 con la participación de Jorge Smith, Melbourne Clark y Guillermo Gibbs en representación de la casa comercial británica Anthony Gibbs \& Sons. La compañía llegó a poseer las salitreras "Carolina” y “La Limeña”, establecimientos y muelles en Iquique, Molle y Junín. Billinghurst, 1889. Los capitales salitreros de Tarapacá, pp. 15-17; 31-32; Crozier, Ronald. 1997. "El salitre hasta la guerra del Pacífico: una revisión". Historia, vol. 30, Santiago de Chile, pp. 78-79.

59 Miller y Greenhill. 2011, "El gobierno y el comercio del salitre", p. 43.

${ }^{60}$ Esteves, Luis. 1971 (1882). Apuntes para la historia económica del Perú, Lima, Centro de Estudios de Población y Desarrollo, p. 140.
} 
Para Dávalos y Lissón, el estanco resultó irrealizable porque la baja del precio en Europa fue desfavorable para el Estado y favorable para el productor salitrero, situación que se contraponía en momentos en que el precio por quintal subía ${ }^{61}$.

En el Perú de los primeros cincuenta años de vida republicana no se conoce ninguna medida que haya sido tan controversial como la del estanco del salitre, pues -como hemos anotadodesde Lima solo se conocía parcialmente lquique y, sobre todo, cómo se había desarrollado la industria salitrera. La participación de los prominentes miembros del Partido Civil, a través de sus bancos, en los intentos por hacer realidad el estanco es un dato para tener cuenta en el fracaso de aquella medida. Por ello una publicación de 1872, entre otras cuestiones que abordó, planteó una pregunta: “¿Quién responde de que á la vuelta de pocos años no estarán comprometidos los valores del estanco, al servicio de un empréstito votado con esa garantía?" ${ }^{\prime 2}$. Pues dadas las condiciones en las cuales se diseñó desde el Congreso y los mecanismos para concretar la medida se puso de manifiesto el enfrentamiento entre dos fuerzas económicas y sociales: los civilistas, que controlaban el gobierno, y los salitreros, que buscaban afianzar sus esfuerzos para sacar adelante una industria que transitaba a formas más modernas de producción, desde lquique.

Finalmente -como afirma Sergio González-, la cuestión del salitre "expresa la temprana contradicción territorial entre centro-periferia al interior de un Estado-nación en América Latina. En este caso, Tarapacá era desde la perspectiva limeña un territorio al borde de la nación, que estuvo siempre en disputa con Bolivia" ${ }^{63}$. Un tema todavía pendiente en la historiografía.

\section{Referencias citadas}

\section{Periódicos}

El Comercio (Iquique, 1873-1874)

El Mercurio de Iquique (Iquique, 1873)

El Peruano (Lima, 1873)

\section{Bibliografía}

Anónimo. 1874. Huano y salitre. Publicaciones hechas por la prensa en defensa de los intereses de la industria salitrera, Lima, imprenta de El Nacional.

\footnotetext{
${ }^{61}$ Dávalos y Lissón, Pedro. 1926. La primera centuria. Causas geográficas, políticas y económicas que han detenido el progreso moral y material del Perú en el primer siglo de su vida independiente, tomo IV, Lima, Librería e imprenta Gil, p. 401.

62 Anónimo. 1872, Impugnación del proyecto del estanco, 1872, p. 12.

${ }^{63}$ González y Lizama. 2019, "El estanco salitrero en Tarapacá", p. 48.
} 
Anónimo. 1872. Impugnación del proyecto de estanco del salitre de Tarapacá, Lima, imprenta de La Patria.

Basadre, Jorge. 1983. Historia de la República del Perú, Lima, Editorial Universitaria.

Bermúdez, Oscar. 1963. Historia del salitre desde sus orígenes hasta la guerra del Pacífico, Santiago, Ediciones de la Universidad de Chile.

Billinghurst, Guillermo. 1889. Los capitales salitreros de Tarapacá, Santiago, imprenta de El Progreso.

Bonilla, Heraclio. 1984. Guano y burguesía en el Perú, Lima, Instituto de Estudios Peruanos.

Bonilla, Heraclio. 1986. "La crisis de 1872", en Bonilla, Heraclio (comp.). Las crisis económicas en la historia del Perú, Lima, Fundación Friedrich Ebert, pp. 167-184.

Calle, Marcos. 2014. “Gildemeister y compañía: una empresa de origen alemán en Tarapacá, 1854-1940”, en González, Sergio y Parodi, Daniel (comps.). Las historias que nos unen. Episodios positivos en las relaciones peruano-chilenas, siglos XIX-XX, Santiago, Ril Editores - Universidad Arturo Prat, pp. 335360.

Camprubi, Carlos. 1957. Historia de los bancos en el Perú (1860-1879), Lima, Editorial Lumen.

Castro, Luis. 2017. "Demanda de ciudadanía, construcción de nación y rentismo minero: los planteamientos regionalistas de los habitantes de la provincia de Tarapacá (1827-1874)", en Temas americanistas, $\mathrm{N}^{\circ} 39$, Sevilla, pp. 37-66.

Castro, Luis. 2019. “'¿Pertenece a Chile?’ Civilización y desierto, rentismo y subordinación: la formación del territorio nacional en el extremo sur del Perú (Tarapacá 1827-1877)", en Estudos IberoAmericanos, Vol. 45, № 1, Porto Alegre, pp. 144-157.

Contreras, Carlos. 1996. "Modernizarse o descentralizar: la difícil disyuntiva de las finanzas peruanas durante la era del guano", en Boletín del Instituto Francés de Estudios Andinos, Tomo 25, № 1, Lima, pp. 125-150.

Contreras, Carlos. 2012. La economía pública en el Perú después del guano y del salitre. Crisis fiscal y élites económicas durante su primer siglo independiente, Lima, Banco Central de Reserva del Perú Instituto de Estudios Peruanos.

Congreso de la República del Perú. 1873. Diario de los debates de la Cámara de Diputados. Congreso Extraordinario, Lima, imprenta de El Nacional.

Crozier, Ronald. 1997. "El salitre hasta la guerra del Pacífico: una revisión", en Historia, vol. 30, Santiago de Chile, pp. 53-126.

Cruchaga, Miguel. 1929. Salitre y guano, Madrid, Editorial Reus.

Dancuart, Emilio. 1907. Anales de la hacienda pública del Perú. Historia y legislación de la República, tomo IV, Lima, imprenta de La Revista.

Dávalos y Lissón, Pedro. 1926. La primera centuria. Causas geográficas, políticas y económicas que han detenido el progreso moral y material del Perú en el primer siglo de su vida independiente, Lima, Librería e Imprenta Gil.

Donoso, Carlos. 2003. "El puerto de Iquique en tiempos de la administración peruana", en Historia, $\mathrm{N}^{\circ}$ 36, Santiago, pp. 123-158. 
Donoso, Carlos. 2007. Estado y sociedad en lquique bajo administración peruana 1821-1873, Santiago, Universidad de Chile, Tesis para optar el grado de doctor en Historia.

Donoso, Carlos. 2018. "Los albores de la industria salitrera en Tarapacá", en Chungara. Revista de Antropología Chilena, vol. 50, N³, Arica, pp. 459-470.

Elguera, Juan. 1874. Memoria presentada por el ministro de Hacienda y Comercio a la legislatura ordinaria de 1874, Lima, imprenta de la Opinión Nacional.

El Nacional. 1874. Revista General del año de 1873. Edición extraordinaria de 1 de enero de 1874. Lima, imprenta de El Nacional.

Esteves, Luis. 1971[1882]. Apuntes para la historia económica del Perú, Lima, Centro de Estudios de Población y Desarrollo.

Flores, Carlos. 2000. "El civilismo y la cuestión del salitre", en Historia. Revista de Historia y Sociedad, $\mathrm{N}^{\circ}$ 1, Lima, pp. 39-47.

Izque, José R. 1874. Memoria que presenta al señor ministro de Hacienda y Comercio el director de administración general. Documentos. Estanco del salitre, Lima, imprenta de El Nacional.

González, Sergio. 2011. "Auge y crisis del nitrato chileno: La importancia de los viajeros, empresarios y científicos, 1830-1919”, en Tiempo Histórico, N² 2, Santiago, pp. 159-178.

González, Sergio. 2012. "La resistencia de los tarapaqueños al monopolio salitrero peruano durante el gobierno de Manuel Pardo, desde el Estanco a la Expropiación (1872-1876)", en Chungara. Revista de Antropología Chilena, vol. 44, N 1, Arica, pp. 101-114.

González, Sergio. 2013. "Las políticas salitreras peruana y chilena. ¿Del monopolio estatal a la libertad económica? (1873-1884)”, en Cuadernos de Historia, №38, Santiago, pp. 39-77.

González, Sergio. 2014. "Las inflexiones de inicio y término del ciclo de expansión del salitre (1872-1919). Una crítica al nacionalismo metodológico", en Diálogo Andino, № 45, Arica, pp. 39-49.

González, Sergio. 2018. "Las primeras estacas del reino salitrero de John Thomas North. El origen del mito", en Cuadernos e Historia, $\mathrm{N}^{\circ} 49$, Santiago, pp. 7-36.

González Sergio y Lizama, Diego. 2019. "El estanco salitrero en Tarapacá y el liberalismo peruano: las influencias "castillista" y "civilista" (1844-1873)", en Aldea Mundo. Revista sobre Fronteras e Integración Regional, $\mathrm{N}^{\circ}$ 48, Tachira, pp. 45-56.

Hernández, Roberto. 1930. El salitre (Resumen histórico desde su descubrimiento y explotación), Valparaíso, Fisher Hermanos.

Hunt, Shane. 1984. "Guano y crecimiento en el Perú del siglo XIX", en HISLA. Revista Latinoamericana de Historia Económica y Social, N IV, Lima, pp. 35-92.

Mc Evoy, Carmen. 1997. La utopía republicana. Ideales y realidades en la formación de la cultura política peruana (1871-1919), Lima, Fondo Editorial Pontificia Universidad Católica del Perú.

Miller, Rory y Greenhill, Robert. 2011. "El gobierno peruano y el comercio del salitre, 1873-1879", en Miller, Rory, Empresas británicas, economía y política en el Perú 1850-1934, Lima, Banco Central de Reserva del Perú - Instituto de Estudios Peruanos, pp. 33-67. 
Morón, Eduardo. 1993. La experiencia de banca libre en el Perú: 1860-1879, Lima, Editorial de la Universidad del Pacífico.

Mücke, Ulrich. 2010. Política y burguesía en el Perú. El Partido Civil antes de la guerra con Chile, Lima, Instituto Francés de Estudios Andinos - Instituto de Estudios Peruanos.

Pardo, Manuel. 1874. Mensage del Excmo. señor D. Manuel Pardo, presidente constitucional de la República a la legislatura ordinaria de 1874, Lima, imprenta del Estado.

Pinto, Julio. 1987. "Valparaíso: metrópoli financiera del boom del salitre", en Estrada, Baldomero y Pinto, Julio, Valparaíso 1536-1986, Valparaíso, Instituto de Historia, Universidad Católica de Valparaíso, pp. 119-150.

Rodríguez, José Manuel. 1895. Estudios económicos y financieros y ojeada sobre la hacienda pública del Perú y la necesidad de su reforma, Lima, Librería, Imprenta y Encuadernación Gil.

Romero, Emilio. 2005. Historia económica del Perú, Lima, Fondo Editorial de la Universidad Nacional Mayor de San Marcos.

Salas, Miriam. 2011. Historia Marítima del Perú: La República 1879 a 1883, tomo XI, volumen 4, Lima, Instituto de Estudios Histórico - Marítimos del Perú.

San Cristóbal, Evaristo. 1945. Manuel Pardo y Lavalle. Vida y obra, Lima, Gil Editores.

Tantaleán, Javier. 1983. Política económico-financiera y formación del Estado: siglo XIX, Lima, Cedep.

Tantaleán, Javier. 2012. La gobernabilidad y el leviatán guanero. Desarrollo, crisis y guerra con Chile, Lima, Banco Central de Reserva del Perú - Instituto de Estudios Peruanos.

Vilar, Pierre. 1980. Crecimiento y desarrollo. Economía e historia, Barcelona, Editorial Ariel. 